\title{
Resolução CEB nํㅜ 3, de 26 de Junho de 1998
}

\section{Institui as Diretrizes Ourriculares Nacionais para o Ensino Médio}

O Presidente da Câmara de Educação Básica do Conselho Nacional de Educação, de conformidade com o disposto no art. 9 § 1ํá, alínea "c", da Lei 9.131, de 25 de novembro de 1995, nos artigos 26, 35 e 36 da Lei 9.394, de 20 de dezembro de 1996, e tendo em vista o Parecer CEB/CNE 15/98, homologado pelo Senhor Ministro da Educação e do Desporto em 25 de junho de 1998, e que a esta se integra,

\section{RESOLVE:}

Art. $1^{\circ}$ As Diretrizes Curriculares Nacionais do Ensino Médio - DCNEM, estabelecidas nesta Resolução, se constituem num conjunto de definições doutrinárias sobre princípios, fundamentos e procedimentos a serem observados na organização pedagógica e curricular de cada unidade escolar integrante dos diversos sistemas de ensino, em atendimento ao que manda a lei, tendo em vista vincular a educação com o mundo do trabalho e a prática social, consolidando a preparação para o exercício da cidadania e propiciando preparação básica para o trabalho.

Art. $2^{\circ}$ A organização curricular de cada escola será orientada pelos valores apresentados na Lei 9.394, a saber:

I - os fundamentais ao interesse social, aos direitos e deveres dos cidadãos, de respeito ao bem comum e à ordem democrática;

II - os que fortaleçam os vínculos de família, os laços de solidariedade humana e de tolerância recíproca.

Art. 3ํ Para observância dos valores mencionados no artigo anterior, a prática administrativa e pedagógica dos sistemas de ensino e de suas escolas, as formas de convivência no ambiente escolar, os mecanismos de 
formulação e implementação de política educacional, os critérios de alocação de recursos, a organização do currículo e das situações de ensino aprendizagem e os procedimentos de avaliação deverão ser coerentes com princípios estéticos, políticos e éticos, abrangendo:

I - a Estética da Sensibilidade, que deverá substituir a da repetição e padronização, estimulando a criatividade, o espírito inventivo, a curiosidade pelo inusitado, e a afetividade, bem como facilitar a constituição de identidades capazes de suportar a inquietação, conviver com o incerto e o imprevisível, acolher e conviver com a diversidade, valorizar a qualidade, a delicadeza, a sutileza, as formas lúdicas e alegóricas de conhecer o mundo e fazer do lazer, da sexualidade e da imaginação um exercício de liberdade responsável.

II - a Política da Igualdade, tendo como ponto de partida o reconhecimento dos direitos humanos e dos deveres e direitos da cidadania, visando à constituição de identidades que busquem e pratiquem a igualdade no acesso aos bens sociais e culturais, o respeito ao bem comum, o protagonismo e a responsabilidade no âmbito público e privado, o combate a todas as formas discriminatórias e o respeito aos princípios do Estado de Direito na forma do sistema federativo e do regime democrático e republicano.

III - a Ética da Identidade, buscando superar dicotomias entre o mundo da moral e o mundo da matéria, o público e o privado, para constituir identidades sensíveis e igualitárias no testemunho de valores de seu tempo, praticando um humanismo contemporâneo, pelo reconhecimento, respeito e acolhimento da identidade do outro e pela incorporação da solidariedade, da responsabilidade e da reciprocidade como orientadoras de seus atos na vida profissional, social, civil e pessoal.

Art. 4ํㅡㄹ As propostas pedagógicas das escolas e os currículos constantes dessas propostas incluirão competências básicas, conteúdos e formas de tratamento dos conteúdos, previstas pelas finalidades do ensino médio estabelecidas pela lei:

I - desenvolvimento da capacidade de aprender e continuar aprendendo, da autonomia intelectual e do pensamento crítico, de modo a ser capaz de prosseguir os estudos e de adaptar-se com flexibilidade a novas condições de ocupação ou aperfeiçoamento;

II - constituição de significados socialmente construídos e reconhecidos como verdadeiros sobre o mundo físico e natural, sobre a realidade social e política;

III - compreensão do significado das ciências, das letras e das artes e do processo de transformação da sociedade e da cultura, em especial as 
do Brasil, de modo a possuir as competências e habilidades necessárias ao exercício da cidadania e do trabalho;

IV - domínio dos princípios e fundamentos científico-tecnológicos que presidem a produção moderna de bens, serviços e conhecimentos, tanto em seus produtos como em seus processos, de modo a ser capaz de relacionar a teoria com a prática e o desenvolvimento da flexibilidade para novas condições de ocupação ou aperfeiçoamento posteriores;

V - competência no uso da língua portuguesa, das línguas estrangeiras e outras linguagens contemporâneas como instrumentos de comunicação e como processos de constituição de conhecimento e de exercício de cidadania.

Art. 5ำ Para cumprir as finalidades do ensino médio previstas pela lei, as escolas organizarão seus currículos de modo a:

I - ter presente que os conteúdos curriculares não são fins em si mesmos, mas meios básicos para constituir competências cognitivas ou sociais, priorizando-as sobre as informações;

II - ter presente que as linguagens são indispensáveis para a constituição de conhecimentos e competências;

III - adotar metodologias de ensino diversificadas, que estimulem a reconstrução do conhecimento e mobilizem o raciocínio, a experimentação, a solução de problemas e outras competências cognitivas superiores;

IV - reconhecer que as situações de aprendizagem provocam também sentimentos e requerem trabalhar a afetividade do aluno.

Art. 6ํㅡㄹ Os princípios pedagógicos da Identidade, Diversidade e Autonomia, da Interdisciplinaridade e da Contextualização, serão adotados como estruturadores dos currículos do ensino médio.

Art. $7^{\circ} \mathrm{Na}$ observância da Identidade, Diversidade e Autonomia, os sistemas de ensino e as escolas, na busca da melhor adequação possível às necessidades dos alunos e do meio social:

I - desenvolverão, mediante a institucionalização de mecanismos de participação da comunidade, alternativas de organização institucional que possibilitem:

a) identidade própria enquanto instituições de ensino de adolescentes, jovens e adultos, respeitadas as suas condições e necessidades de espaço e tempo de aprendizagem;

b) uso das várias possibilidades pedagógicas de organização, inclusive espaciais e temporais; 
c) articulações e parcerias entre instituições públicas e privadas, contemplando a preparação geral para o trabalho, admitida a organização integrada dos anos finais do ensino fundamental com o ensino médio;

II - fomentarão a diversificação de programas ou tipos de estudo disponíveis, estimulando alternativas, a partir de uma base comum, de acordo com as características do alunado e as demandas do meio social, admitidas as opções feitas pelos próprios alunos, sempre que viáveis técnica e financeiramente;

III - instituirão sistemas de avaliação e/ou utilizarão os sistemas de avaliação operados pelo Ministério da Educação e do Desporto, a fim de acompanhar os resultados da diversificação, tendo como referência as competências básicas a serem alcançadas, a legislação do ensino, estas diretrizes e as propostas pedagógicas das escolas;

IV - criarão os mecanismos necessários ao fomento e fortalecimento da capacidade de formular e executar propostas pedagógicas escolares características do exercício da autonomia;

V - criarão mecanismos que garantam liberdade e responsabilidade das instituições escolares na formulação de sua proposta pedagógica, e evitem que as instâncias centrais dos sistemas de ensino burocratizem e ritualizem o que, no espírito da lei, deve ser expressão de iniciativa das escolas, com protagonismo de todos os elementos diretamente interessados, em especial dos professores;

VI - instituirão mecanismos e procedimentos de avaliação de processos e produtos, de divulgação dos resultados e de prestação de contas, visando desenvolver a cultura da responsabilidade pelos resultados e utilizando os resultados para orientar ações de compensação de desigualdades que possam resultar do exercício da autonomia.

Art. 8ํNa observância da Interdisciplinaridade as escolas terão presente que:

I - a Interdisciplinaridade, nas suas mais variadas formas, partirá do princípio de que todo conhecimento mantém um diálogo permanente com outros conhecimentos, que pode ser de questionamento, de negação, de complementação, de ampliação, de iluminação de aspectos não distinguidos;

II - o ensino deve ir além da descrição e procurar constituir nos alunos a capacidade de analisar, explicar, prever e intervir, objetivos que são mais facilmente alcançáveis se as disciplinas, integradas em áreas de conhecimento, puderem contribuir, cada uma com sua especificidade, para o estudo comum de problemas concretos, ou para o desenvolvimento de projetos de investigação e/ou de ação; 
III - as disciplinas escolares são recortes das áreas de conhecimentos que representam, carregam sempre um grau de arbitrariedade e não esgotam isoladamente a realidade dos fatos físicos e sociais, devendo buscar entre si interações que permitam aos alunos a compreensão mais ampla da realidade;

IV - a aprendizagem é decisiva para o desenvolvimento dos alunos, e por esta razão as disciplinas devem ser didaticamente solidárias para atingir esse objetivo, de modo que disciplinas diferentes estimulem competências comuns, e cada disciplina contribua para a constituição de diferentes capacidades, sendo indispensável buscar a complementaridade entre as disciplinas a fim de facilitar aos alunos um desenvolvimento intelectual, social e afetivo mais completo e integrado;

V - a característica do ensino escolar, tal como indicada no inciso anterior, amplia significativamente a responsabilidade da escola para a constituição de identidades que integram conhecimentos, competências e valores que permitam o exercício pleno da cidadania e a inserção flexível no mundo do trabalho.

Art. 9ำ $\mathrm{Na}$ observância da Contextualização as escolas terão presente que:

I - na situação de ensino e aprendizagem, o conhecimento é transposto da situação em que foi criado, inventado ou produzido, e por causa desta transposição didática deve ser relacionado com a prática ou a experiência do aluno a fim de adquirir significado;

II - a relação entre teoria e prática requer a concretização dos conteúdos curriculares em situações mais próximas e familiares do aluno, nas quais se incluem as do trabalho e do exercício da cidadania;

III - a aplicação de conhecimentos constituídos na escola às situações da vida cotidiana e da experiência espontânea permite seu entendimento, crítica e revisão.

Art. 10ำ A base nacional comum dos currículos do ensino médio será organizada em áreas de conhecimento, a saber:

I - Linguagens, Códigos e suas Tecnologias, objetivando a constituição de competências e habilidades que permitam ao educando:

a) Compreender e usar os sistemas simbólicos das diferentes linguagens como meios de organização cognitiva da realidade pela constituição de significados, expressão, comunicação e informação.

b) Confrontar opiniões e pontos de vista sobre as diferentes linguagens e suas manifestações específicas. 
c) Analisar, interpretar e aplicar os recursos expressivos das linguagens, relacionando textos com seus contextos, mediante a natureza, função, organização, estrutura das manifestações, de acordo com as condições de produção e recepção.

d) Compreender e usar a língua portuguesa como língua materna, geradora de significação e integradora da organização do mundo e da própria identidade.

e) Conhecer e usar língua(s) estrangeira(s) moderna(s) como instrumento de acesso a informações e a outras culturas e grupos sociais.

f) Entender os princípios das tecnologias da comunicação e da informação, associá-las aos conhecimentos científicos, às linguagens que lhes dão suporte e aos problemas que se propõem solucionar.

g) Entender a natureza das tecnologias da informação como integração de diferentes meios de comunicação, linguagens e códigos, bem como a função integradora que elas exercem na sua relação com as demais tecnologias.

h) Entender o impacto das tecnologias da comunicação e da informação na sua vida, nos processos de produção, no desenvolvimento do conhecimento e na vida social.

i) Aplicar as tecnologias da comunicação e da informação na escola, no trabalho e em outros contextos relevantes para sua vida.

II - Ciências da Natureza, Matemática e suas Tecnologias, objetivando a constituição de habilidades e competências que permitam ao educando:

a) Compreender as ciências como construções humanas, entendendo como elas se desenvolvem por acumulação, continuidade ou ruptura de paradigmas, relacionando o desenvolvimento científico com a transformação da sociedade.

b) Entender e aplicar métodos e procedimentos próprios das ciências naturais.

c) Identificar variáveis relevantes e selecionar os procedimentos necessários para a produção, análise e interpretação de resultados de processos ou experimentos científicos e tecnológicos.

d) Compreender o caráter aleatório e não determinístico dos fenômenos naturais e sociais e utilizar instrumentos adequados para medidas, determinação de amostras e cálculo de probabilidades.

e) Identificar, analisar e aplicar conhecimentos sobre valores de variáveis, representados em gráficos, diagramas ou expressões algébricas, 
realizando previsão de tendências, extrapolações e interpolações e interpretações.

f) Analisar qualitativamente dados quantitativos representados gráfica ou algebricamente relacionados a contextos sócio-econômicos, científicos ou cotidianos

g) Apropriar-se dos conhecimentos da física, da química e da biologia e aplicar esses conhecimentos para explicar o funcionamento do mundo natural, planejar, executar e avaliar ações de intervenção na realidade natural.

h) Identificar, representar e utilizar o conhecimento geométrico para o aperfeiçoamento da leitura, da compreensão e da ação sobre a realidade.

i) Entender a relação entre o desenvolvimento das ciências naturais e o desenvolvimento tecnológico e associar as diferentes tecnologias aos problemas que se propuseram e propõem solucionar.

j) Entender o impacto das tecnologias associadas às ciências naturais na sua vida pessoal, nos processos de produção, no desenvolvimento do conhecimento e na vida social.

I) Aplicar as tecnologias associadas às ciências naturais na escola, no trabalho e em outros contextos relevantes para sua vida.

m) Compreender conceitos, procedimentos e estratégias matemáticas e aplicá-las a situações diversas no contexto das ciências, da tecnologia e das atividades cotidianas.

III - Ciências Humanas e suas Tecnologias, objetivando a constituição de competências e habilidades que permitam ao educando:

a) Compreender os elementos cognitivos, afetivos, sociais e culturais que constituem a identidade própria e dos outros.

b) Compreender a sociedade, sua gênese e transformação e os múltiplos fatores que nelas intervêm, como produtos da ação humana; a si mesmo como agente social; e os processos sociais como orientadores da dinâmica dos diferentes grupos de indivíduos.

c) Compreender o desenvolvimento da sociedade como processo de ocupação de espaços físicos e as relações da vida humana com a paisagem, em seus desdobramentos político-sociais, culturais, econômicos e humanos.

d) Compreender a produção e o papel histórico das instituições sociais, políticas e econômicas, associando-as às práticas dos diferentes grupos e atores sociais, aos princípios que regulam a convivência em socie- 
dade, aos direitos e deveres da cidadania, à justiça e à distribuição dos benefícios econômicos.

e) Traduzir os conhecimentos sobre a pessoa, a sociedade, a economia, as práticas sociais e culturais em condutas de indagação, análise, problematização e protagonismo diante de situações novas, problemas ou questões da vida pessoal, social, política, econômica e cultural.

f) Entender os princípios das tecnologias associadas ao conhecimento do indivíduo, da sociedade e da cultura, entre as quais as de planejamento, organização, gestão, trabalho de equipe, e associá-las aos problemas que se propõem resolver.

g) Entender o impacto das tecnologias associadas às ciências humanas sobre sua vida pessoal, os processos de produção, o desenvolvimento do conhecimento e a vida social.

h) Entender a importância das tecnologias contemporâneas de comunicação e informação para o planejamento, gestão, organização, fortalecimento do trabalho de equipe.

i) Aplicar as tecnologias das ciências humanas e sociais na escola, no trabalho e outros contextos relevantes para sua vida.

$\S 1^{\circ} \mathrm{A}$ base nacional comum dos currículos do ensino médio deverá contemplar as três áreas do conhecimento, com tratamento metodológico que evidencie a interdisciplinaridade e a contextualização.

$\S 2^{\circ}$ As propostas pedagógicas das escolas deverão assegurar tratamento interdisciplinar e contextualizado para: rios;

a) Educação Física e Arte, como componentes curriculares obrigató-

b) Conhecimentos de filosofia e sociologia necessários ao exercício da cidadania.

Art. $11^{\circ} \mathrm{Na}$ base nacional comum e na parte diversificada será observado que:

I - as definições doutrinárias sobre os fundamentos axiológicos e os princípios pedagógicos que integram as DCNEM aplicar-se-ão a ambas;

II - a parte diversificada deverá ser organicamente integrada com a base nacional comum, por contextualização e por complementação, diversificação, enriquecimento, desdobramento, entre outras formas de integração;

III - a base nacional comum deverá compreender, pelo menos, $75 \%$ (setenta e cinco por cento) do tempo mínimo de 2.400 (duas mil e quatrocentas) horas, estabelecido pela lei como carga horária para o ensino médio; 
IV - além da carga mínima de 2.400 horas, as escolas terão, em suas propostas pedagógicas, liberdade de organização curricular, independentemente de distinção entre base nacional comum e parte diversificada;

$\mathrm{V}$ - a língua estrangeira moderna, tanto a obrigatória quanto as optativas, serão incluídas no cômputo da carga horária da parte diversificada.

Art. $12^{\circ}$ Não haverá dissociação entre a formação geral e a preparação básica para o trabalho, nem esta última se confundirá com a formação profissional.

$\S 1^{\circ}$ A preparação básica para o trabalho deverá estar presente tanto na base nacional comum como na parte diversificada.

$\S 2^{\circ} \mathrm{O}$ ensino médio, atendida a formação geral, incluindo a preparação básica para o trabalho, poderá preparar para o exercício de profissões técnicas, por articulação com a educação profissional, mantida a independência entre os cursos.

Art. $13^{\circ}$ Estudos concluídos no ensino médio, tanto da base nacional comum quanto da parte diversificada, poderão ser aproveitados para a obtenção de uma habilitação profissional, em cursos realizados concomitante ou seqüencialmente, até o limite de $25 \%$ (vinte e cinco por cento) do tempo mínimo legalmente estabelecido como carga horária para o ensino médio.

Parágrafo único. Estudos estritamente profissionalizantes, independentemente de serem feitos na mesma escola ou em outra escola ou instituição, de forma concomitante ou posterior ao ensino médio, deverão ser realizados em carga horária adicional às 2.400 horas (duas mil e quatrocentas) horas mínimas previstas na lei.

Art. 14ํㅡㄹ Caberá, respectivamente, aos órgãos normativos e executivos dos sistemas de ensino o estabelecimento de normas complementares e políticas educacionais, considerando as peculiaridades regionais ou locais, observadas as disposições destas diretrizes.

Parágrafo único. Os órgãos normativos dos sistemas de ensino deverão regulamentar o aproveitamento de estudos realizados e de conhecimentos constituídos tanto na experiência escolar como na extra-escolar.

Art. 15ํㅡㄹ Esta Resolução entra em vigor na data de sua publicação e revoga as disposições em contrário.

Ulysses de Oliveira Panisset Presidente da Câmara de Educação Básica 